\title{
Survival of discarded plaice ( Pleuronectes platessa ) from Norway lobster ( Nephrops norvegicus ) otter-trawl fishery
}

Eskelund, Marc; Methling, Caroline; Skov, Peter Vilhelm; Madsen, Niels

Published in:

Journal of Applied Ichthyology

Link to article, DOI:

10.1111/jai.13888

Publication date:

2019

Document Version

Peer reviewed version

Link back to DTU Orbit

Citation (APA):

Eskelund, M., Methling, C., Skov, P. V., \& Madsen, N. (2019). Survival of discarded plaice (Pleuronectes

platessa ) from Norway lobster ( Nephrops norvegicus ) otter-trawl fishery. Journal of Applied Ichthyology, 35(3), 645-654. https://doi.org/10.1111/jai.13888

\section{General rights}

Copyright and moral rights for the publications made accessible in the public portal are retained by the authors and/or other copyright owners and it is a condition of accessing publications that users recognise and abide by the legal requirements associated with these rights.

- Users may download and print one copy of any publication from the public portal for the purpose of private study or research.

- You may not further distribute the material or use it for any profit-making activity or commercial gain

- You may freely distribute the URL identifying the publication in the public portal 


\title{
1 Authors last version before publication
}

2

\section{Survival of discarded plaice (Pleuronectes platessa) from Norway lobster (Nephrops norvegicus) otter-trawl fishery}

\author{
Marc Eskelund ${ }^{1}$, Caroline Methling ${ }^{1}$, Peter Vilhelm Skov ${ }^{1}$, Niels Madsen²*
}

${ }^{1}$ Technical University of Denmark, National Institute of Aquatic Resources, North Sea Science Park, PO Box 101, DK-9850, Hirtshals, Denmark

${ }^{2}$ Section of Biology and Environmental Science, Department of Chemistry and Bioscience, Aalborg University, Fredrik Bajers Vej 7H, 9220 Aalborg, Denmark.

${ }^{*}$ Corresponding author

\section{Summary}

The introduction of landing obligations in the European Union common fisheries policy, has increased the focus on discard survival. Since species with scientifically proven high survival rates may be exempted from the landing obligations, the economic significance for the fishing industry is large. Landing obligations include individuals below the minimum conservation reference size (MCRS), which are not allowed to be sold for human consumption. The Norway lobster (Nephrops norvegicus) fishery is a high value fishery, but with a substantial amount of bycatch of plaice (Pleuronectes platessa) below the MCRS. In the present study, observations were made on the short-term survival of plaice at or below the MCRS, discarded from a small otter board trawler targeting Nephrops in Skagerrak (ICES 3a). The average short-term survival of plaice was $15 \%$ at haul level, ranging from 0 $39 \%$, after 10 days of captive observation. Survival significantly decreased with time on deck and the retention of debris in the codend $(P<0.0001)$, while survival was not correlated to size. Vitality assessments, using a combined reflex impairment and injury score, were tested as predictor of survival and were significantly associated to survival $(P<0.0001)$ both for individual fish and when grouped by hauls. Seabird predation behaviour was assessed and 
32 it was estimated that seabirds predated or pursued $85 \%$ of discarded plaice below the MCRS.

Key words: Bycatch, Discard Ban, Discard survival, Injury Assessment, Landing obligation, Reflex action mortality predictor, RAMP, Vitality assessment

\section{1 | Introduction}

High discard rates are found in several European fisheries (Uhlmann et al., 2014). A central component of the reform of the European Union common fisheries policy (CFP) is a plan for gradual elimination of discards by landing obligations, where all individuals of certain commercial species are landed (Sardà et al., 2015; Uhlmann et al., 2014; Sigurðardóttir et al., 2015). However, individuals below a defined minimum conservation reference size (MCRS) have a low market value because they are not permitted sold for human consumption and in some cases they might even constitute an extra expense for the fishers (Condie et al., 2013).

The Nephrops (Nephrops norvegicus, Norway lobster) otter-trawl fishery is the most important commercial demersal fishery for human consumption in Kattegat and Skagerrak (Frandsen et al., 2009, 2010; Krag et al., 2008; Madsen et al., 2010; Feekings et al., 2012). It is also of high commercial importance in other European areas (Catchpole and Revill, 2007). To retain Nephrops the fishery uses relatively small mesh sizes. The mesh size in the codend is around $90 \mathrm{~mm}$ (inside mesh opening) in the Danish Nephrops fishery, which is smaller than the $120 \mathrm{~mm}$ used when targeting fish species for human consumption. Consequently, high bycatch and discard rates are often associated with European Nephrops fisheries (Bergmann et al., 2002; Catchpole et al., 2005; Catchpole and Revill, 2007,

58 Uhlmann et al., 2014). In the Skagerrak and the adjacent Kattegat discards are reported to 59 be larger than the landings in the crustacean fisheries (Uhlmann, 2014).

60 Plaice (Pleuronectes platessa) is an important commercial species that is often caught 61 and discarded in Nephrops otter-trawl fisheries in Kattegat and Skagerrak (Feekings et al. 62 2012) and in otter-trawl fisheries in the North Sea (Madsen et al., 2013). The landing 
63

64

obligation is therefore expected to have implications for the Nephrops fishery, typically having high discard rates.

An exemption for the landing obligation is described for species with scientific evidence of high survival rates (Article 15.4b of Regulation (EU) No 1380/2013). The short-term discard survival of plaice has been studied in demersal beam- and otter-trawling indicating a high degree of variability in estimated survival rates. The short-term survival of plaice in beam-trawling was estimated to vary between 2-24\% (van Beek et al., 1990), 39-40\% (Kaiser and Spencer, 1995), 27-57\% (Revill et al., 2013), and 48-69\% (Depestele et al., 2014), with tow duration varying between 60-120 minutes and observation periods of 3-5 days. In otter-trawls, van Beek et al. (1990), Millner et al. (1993) and Methling et al. (2017) and Morfin et al. (2017) estimated a short-term discard survival of plaice at haul level of 034\%, 63-100\% and 77-100\%, respectively; and at seasonal level 45-67\% (Morfin et al. (2017), with tow duration between 60-305 minutes and 4-10 days observation periods. None of these studies have examined the discard survival of plaice where Nephrops is the target species.

The main objective of the present study is to estimate the short-term survival of plaice caught in otter-trawls in a representative Nephrops fishery. The focus of this study was individuals below the minimum landing size (MLS) of $270 \mathrm{~mm}$ that corresponds to the minimum conservation reference sizes (MCRS, henceforth used), as specified in the CFP. Discard of plaice above MCRS is believed to be minimal since the fishery is not quota limited. A further objective is to make a quantitative vitality assessment (ICES, 2014a, b), by examination of injuries and reflex impairment on caught individuals. This is to further explore the possibility of developing a methodology to predict short-term survival since this approach has shown potential in previous studies (Davis and Ottmar, 2006, Davis, 2007, 2010, Humborstad et al., 2009), including recent studies on plaice (Uhlmann et al., 2016; Methling et al., 2017).

Previous studies indicates that discards are an important food source for seabirds (Bicknell et al., 2013; Votier et al., 2013; Depestele et al., 2016) and the predation by seabirds might therefore add an additional unquantified contribution to overall discard survival. Consequently, a study was performed to examine the feeding behaviour of seabirds surrounding the vessel in response to discarding of plaice. 


\section{2 | Materials and methods}

\subsection{Sea trials}

99 Sea trials were conducted from the Danish commercial fishing vessel "Tana" (RI286) in the 100 South-Eastern part of Skagerrak (ICES Division IIla) during June 2015. The vessel 101 measured $11.7 \mathrm{~m}$ and was powered by a $125 \mathrm{~kW}$ diesel engine. The vessel fished with its 102 own commercial Nephrops otter-board trawl in a single rig. The head line height of the trawl was around $1.2 \mathrm{~m}$ and the horizontal trawl opening around $10 \mathrm{~m}$. The codend had 80 open meshes in circumference and was 30 meshes long. Codend netting was made of single polyethylene twine with a mesh size of $89.8 \pm 2.6 \mathrm{~mm}$ (average (AVG) \pm standard deviation (SD); $N=24$ ), measured with an ICES mesh gauge (Fonteyne, 2007).

Sea trials were conducted following commercial seasonal practices for smaller vessels fishing at night and a 3 hours tow duration. The vessel departed from harbour in the evening and returned before noon the next day. On each fishing trip, 2-3 hauls were conducted in the same area resulting in 7 experimental and 2 control hauls (Table 1). Towing speed was maintained as constant as possible for all hauls with a speed of $2.3 \pm 0.03$ knots (AVG \pm SD). The duration of all experimental tows was 180 minutes, except one haul, which lasted 160 minutes due to minor technical complications with the trawl. The duration of the 2 control tows was 15 minutes. Data loggers (from Star-Oddi) were attached to the codend to record salinity and temperature during 2 of the hauls.

At the end of the haul the trawl was lifted out of the water and the codend was emptied from a height of $\sim 1 \mathrm{~m}$ into a fish pound $(2 \times 2 \mathrm{~m})$ filled with sea water. Then the conveyor belt was started transporting the catch to a $0.5 \mathrm{~m}^{2}$ sorting table. The catch was continuously emptied from the fish pound and sorted. Seawater was regularly filled into the fish pound to be able to move the catch towards the conveyor belt, which is commercial practice for this

\subsection{Sampling procedure}

125 Plaice collected for the experiment were sampled from the sorting table, one individual at a

126 time. Plaice estimated by eye to be below MCRS where collected randomly by taking the 
first and nearest arriving on the sorting table. From each haul approximately 20 individuals

128 were selected, which corresponds the general time period for commercial sorting of the 129 catch. They were all length measured and assessed individually for injuries and impairment 130 of reflexes. Plaice was tagged individually with a numbered t-bar tag placed near the caudal 131 peduncle on the side of the anal fin using a tagging gun (Mark II, Avery Dennison, 132 Massachusetts, USA).

\subsection{Monitoring experimental fish}

135

Assessments of reflex impairment (reflex action mortality predictor, RAMP) were performed in a separate $35 \mathrm{~L}$ water-filled box. To reduce handling time, only 3 different reflex responses were selected from a list of 6 previously tested on plaice (Methling et al., 2017). A score of 1 was given if a reflex was absent and a score of 0 if a reflex was present (see Table 2 for descriptions of reflexes). We found that the chosen reflexes are relatively subjective and easy to handle, particularly in poor weather conditions and at night time.

Physical injuries were evaluated according to the occurrence of damages described in Table 3. Individuals scored 0 if the damage was absent, or 1 if the damage was present. To take into account the severity of abrasions, bleeding and wounds, an individual assessed with the most severe level of injury would also be scored in the lower tier. Therefore, an individual with internal organ exposure would by definition also have a deep wound, and a deep wound would also count as a superficial wound. An exception was protruding intestines that is likely caused by physical pressure in the fish pound or squeezing while towing or hauling the gear, but without occurrence of wounding and bleeding.

The time from being lifted out of water until placed in on-board tanks was recorded for each individual. After the completion of vitality assessment tests and measures, the tagged

152 individual was placed in hard plastic transport container $(85 \times 65 \times 25 \mathrm{~cm})$, with drilled out 153 holes allowing for water exchange, that were placed in $300 \mathrm{~L}$ water tanks $(91 \times 72 \times 66 \mathrm{~cm})$ 154 installed on the deck (Figure 1) having room for two transport containers. A maximum of 40 155 plaice was held simultaneously in one on-board tank. The water in the $300 \mathrm{~L}$ tanks was 156 refreshed by a deck pump using surface water. Oxygen content was regularly checked using 157 a hand-held meter (Polaris, Oxyguard, Denmark). 
In the two control hauls, the codend was emptied directly into a $90 \mathrm{~L}$ container with sea water and 20 individuals were transferred directly into transport containers and placed in the on-board $300 \mathrm{~L}$ tanks as non-treated controls. Additional 20 individuals were subjected to vitality assessments using the same procedure as for the experimental individuals. All other procedures for the control were the same as described for experimental hauls.

In the harbour the transport containers were moved into a large $1000 \mathrm{~L}$ insulated tank $(148 \times 117 \times 97 \mathrm{~cm})$ with chilled $\left(\sim 10^{\circ} \mathrm{C}\right)$ oxygenated seawater. Tanks were transported by truck to holding facilities about $50 \mathrm{~km}$ from the landing harbour where plaice were moved to two large observation tanks each with around $6000 \mathrm{~L}$ of filtered seawater with a constant flow of $\sim 2 \mathrm{~L} / \mathrm{min}$. Plaice were divided between the two tanks with one control group in each tank. The temperature and oxygen saturation in the holding tanks was measured daily and was $(A V G \pm S D) 16.3 \pm 0.4{ }^{\circ} \mathrm{C}$ and $78.2 \pm 3.4 \%$, and $16.3^{\circ} \mathrm{C} \pm 0.4$ and $81.9 \pm 5.0 \%$ for tank 1 and 2 respectively.

When transferring plaice to the observation tanks, a screening for dead individuals was performed. Assessment of mortality was based on the onset of rigor mortis and colour of the gills. In case of doubt the individual was placed in a quarantine box in the holding tank. The quarantine box was a $90 \mathrm{~L}$ plastic container with drilled out holes so that it was emerged just below the surface to allow a free flow of oxygenated seawater. This enabled easy observation and removal of dead individuals with minimal risk of disturbance and possible infections to the remaining fish that mainly stayed at the bottom of the tanks.

\subsection{Seabird predation behaviour}

A total of 81 dead plaice were selected from the catch, with a total length (AVG \pm SD) of 229 $\pm 34 \mathrm{~mm}$ (range: 150-299 mm). One by one plaice were slipped down the vessels chute leading from the sorting table directly over the side of the ship. The behavioural response of 184 the seabirds was divided into 4 categories: "Attempting", when the seabirds pursued a fish, 185 but discontinued the effort (almost) immediately. "Eaten", when there was positive 186 confirmation that a seabird captured and succeeded to swallow a fish. "No reaction", in the cases where no seabirds pursued a fish. "Unknown", when the seabirds pursued the fish and captured it, but flew outside of the field of view, so the final outcome could not be 
determined. The experiment was carried out in the morning during daylight at a cruising speed of approximately 1.5 knots.

\subsection{Short-term survival}

Including sea trials, the entire experimental period lasted 14 days, with an observation period of 10 days. This was expected to be sufficient time to observe any short-term fishing related mortality, as the majority of mortality during discard survival studies occurs within the first days (Wassenberg and Hill, 1993; Methling et al., 2017). The holding tanks were inspected for dead individuals and oxygen saturation recorded at 24 hour intervals during the observation period to reduce potentially stress.

A hand held telescopic fishing net was used to examine fish by a gentle nudge. An individual was identified as healthy if it avoided the net, while non-responding individuals and individuals lying blind side up were examined for rigor mortis and gill colouration. In the case of fully developed rigor mortis and grey gills the individual was assumed dead and removed from the tank. If either of these two signs were not present or clear, e.g. tissue still soft but grey coloured gills, they were transferred to the quarantine box

\subsection{Modelling and statistical analysis}

The survival probability across time was assessed by the Kaplan-Meier estimator (Kaplan and Meier, 1958), i.e. the accumulated product of the fractions of individuals at risk for each time interval between observed deaths:

$$
\hat{S}(t)=\prod_{t_{i} \leq t} \frac{n_{i}-d_{i}}{n_{i}}
$$

where $d_{i}$ is the number of deaths during the time interval $\left[t_{i}-1 ; t_{i}\right]$ and $n_{i}$ is the remaining individuals at risk at time $t_{i}$. A log-rank Mantel-Cox test was used to compare survival probabilities.

Vitality impairment scores were calculated by combining the RAMP test score and the injury assessment score (Uhlmann et al., 2016). Each individual, $i$, received a vitality impairment score $\left(v i_{i}\right)$ of 0 to 1 ( 0 = no impairment; 1 = full impairment) calculated from: 


$$
v i_{i}=\frac{R A M P_{i}+\operatorname{Injury} y_{i}}{v i_{\max }}
$$

where $\mathrm{RAMP}_{i}$ and Injury ${ }_{i}$ is the RAMP and injury score, respectively, and $v i_{\text {max }}$ is the maximum possible impairment.

The correlation between vitality impairment score and mortality was tested using Spearman's rank order test, and the relationship fitted to a logistic regression model. Student's t-test was used to compare averages for normally distributed data with equal variance and Mann-Whitney $U$ test to compare medians if those assumptions were not met. Statistical significance was accepted at $P \leq 0.05$.

\section{3 | Results}

\subsection{Sea trials}

Over the span of 10 sea days, 7 experimental hauls and 2 controls hauls were completed. As typically for Nephrops trawling, the codend contained large amounts of mud and clay, being the preferred sediment by Nephrops (Rice and Chapman, 1971). However, in 5 out of the 7 experimental hauls, the codend contained unusually large amount of debris consisting of mud and large pieces of peat (estimated weight: $50-70 \mathrm{~kg}$ ). Hauls were hereafter labelled as either "dirty" or "clean". The measured seabed temperature (AVG \pm SD) was $12.6 \pm 0.4^{\circ}$ C (range: 11.5-14.1) and average salinity was 31.6 \pm 0.4 PSU (range: $30.8-33.0 ; \mathrm{N}=820$ ). Deck temperature between 13 and 20 degrees, were recorded when sorting the catch, during the trials period.

\subsection{Short-term discard survival}

A total of 216 plaice were sampled during the 7 experimental and 2 control tows, kept under captive observation and short-term survival was recorded (Table 4).

Kaplan-Meier survival estimates for experimental and control hauls are shown in Figure 
253 hauls and between $84-100 \%$ in the 2 control hauls. The survival probabilities (AVG \pm SD) in 254 the method control: $89 \%$ and untreated control: $100 \%(S D=0.0)$, were not significantly 255 different (Log-rank Mantel-Cox test: $X^{2}(4, N=78)=6.8$; $\left.P>0.05\right)$, but significantly higher than 256 the average survival (15\%) in the experimental hauls (Log-rank Mantel-Cox test: $X^{2}(1, N=212)$ $257=132.5 ; P<0.0001)$.

\subsection{Clean and dirty hauls}

When divided into "clean" and "dirty" hauls (Figure 2B), the average survival in "clean" hauls (no large debris or excessive amount of sediment) reached 37\%, whereas in "dirty" hauls, average survival reached $5 \%$ at the end of the 10 days observation period. In one haul, where several large pieces of peat were retained in the codend, all individuals died within three days of observation. The difference in survival between "clean" and "dirty" hauls was significantly different (Log-rank Mantel-Cox test: $\left.X^{2}(1, N=133)=25.4 ; P<0.0001\right)$.

\subsection{Time on deck and size}

The total time spent on deck including handling (vitality assessment and tagging) affected survival, with a significant negative correlation between the number of days surviving and 273 deck + handling time (Spearman's $\rho=-0.45 ; N=113 ; P<0.0001$ ). The deck + handling 274 time (AVG \pm SD) for surviving individuals: $21 \pm 15$ minutes (range: 0-49; $N=20$ ) was 275 significantly lower than for dead individuals: $31 \pm 17$ minutes (range 4-69; $\mathrm{N}=113$ ) (Mann276 Whitney $U=745 ; n 1=113$; $n 2=20 ; P=0.016$; two-tailed). Survival was not size dependent 277 and there was no significant difference in total length (AVG \pm SD) between surviving: $234 \pm$ $27831.8 \mathrm{~mm}(\mathrm{~N}=20)$, and dead individuals: $229 \pm 23.6 \mathrm{~mm}(\mathrm{~N}=113)$, (Student's t-test: $\mathrm{P}>$ 279 0.05). 
283 The most common injuries observed were scale loss and fin fraying, followed by bleeding and abrasion (Table 4). There were a few individuals with wounds, only very few individuals with deeper wounds and no individuals with internal organs exposed.

There was a significant correlation between vitality impairment and survival (Spearman's rank test: $\rho=0.70 ; N=172 ; P<0.0001$ ), with vitality impairment ranging from $0 \%$ to $62 \%$ in surviving individuals and from $8 \%$ to $77 \%$ in individuals that died (Figure 3A). To predict survival based on vitality impairment, a logistic regression model was fitted to individual observations $(N=172)$ and showed a significant association between the probability of survival and vitality impairment score (F-test: $F=109 ; P<0.001 ; R^{2}=0.56$ ) (Figure 3A).

A significant correlation between vitality impairment score and average survival, grouped by hauls, was also found (Spearman's rank test: $\rho=0.77 ; \mathrm{N}=53$; $\mathrm{P}<0.0001$ ) (Figure 3B). The logistic regression model fitted to the grouped observations $(N=53)$ showed a significant association between the probability of survival and vitality impairment score ( $F$ test: $\left.F=48 ; P<0.001, R^{2}=0.66\right)$. Between the two regression models, the model based on grouped observations, was a slightly better predictor of survival with a larger degree explained by vitality impairment $\left(R^{2}=0.66\right)$, than if based on individual observations $\left(R^{2}=\right.$ 0.56).

\subsection{Seabird predation behaviour}

The seabirds observed in proximity to the vessel were mainly great black-backed gulls (Larus marinus) and European herring gulls (Larus argentatus). The reactions of seabirds to plaice of different sized slipped from the side of the vessel are summarized in Figure 4. All individuals <198 mm were eaten. When size increased the seabirds were no longer able swallow the plaice (the largest individual observed eaten was $240 \mathrm{~mm}$ ), but either pursued and quickly discontinued or disappeared out of sight with the discarded fish. With individuals larger than $240 \mathrm{~mm}$, seabirds often pursued a fish but discontinued the effort almost immediately. Below the MCRS $(270 \mathrm{~mm}), 85 \%$ of plaice was eaten or pursued (attempt discontinued or unknown fate).

\section{4 | Discussion}


316 The overall short-term discard survival of the experiment was $15 \%$, ranging from 0 to $39 \%$ 317 for individual tows. This is within previously examined discard survival proportions from 318 some beam and otter trawls studies (van Beek et al., 1990; Kaiser and Spencer, 1995; Revill 319 et al., 2013; Depestele et al., 2014). Towing durations was however shorter in those studies 320 (maximum 2 hours). The tow duration is thought to have an impact on the discard survival 321 (Broadhurst et al., 2006) since the catch weight will increase and the fish is expected to 322 suffer from stress and physical damages. Millner (1993) estimated a high discard survival 323 (63-93\%), however the fishing depth was only 5-20 m, the tow duration only 120 minutes 324 and the experiment was done on fewer individuals. Furthermore, the survival curves reported do not seem to reach a horizontal asymptote at the end of the observation period, indicating that the survival might be underestimated. The higher discard survival rates (4567\%) estimated in a recent study (Morfin et al., 2017), was from a more directed plaice fishery (not Nephrops).

The vessel used in our experiment is in the lower size category for the Nephrops fishing fleet, catches and towing times will often be higher for trawlers larger than the one used in the present study, which might have negative consequences on survival probability. A recent experiment conducted from the same vessel with the same towing duration but in a directed plaice fishery during winter season, estimated an average discard survival of $89 \%$ (Methling et al., 2017). The marked difference in survival between studies could be due to the presence of the excessive amount of sediment and debris in the codend causing further abrasion injuries together with the Nephrops shells, higher temperatures (air and water) in the present study or a combination of both.

The high survival of the control group suggest that the experimental conditions were not the primary source of mortality. There was difference in temperature between seabed and holding tanks, but both temperatures are within the tolerance level of the plaice and should 341 not affect its general condition (Clarke and Johnston, 1999). However, several survivors 342 showed signs of irritation and beginning inflammation around the tag position in the post343 experiment examinations, which suggests that this tagging method could have a negative effect on the condition of the fish.

Wassenberg and Hill (1993) suggest that the majority of mortality for plaice occurs within the first 3 days. The mortality in the present experiment was highest in the first 4 days, but 
the survival curve did not level off until day 6. A horizontal asymptote of survival was reached after around 8 days, suggesting the observation period was sufficient to observe fishery related short term survival, but longer observation period might be necessary to include mortality caused by secondary factors, e.g. disease or starvation. A fasting plaice would not die from starvation in the time period of the present experiment according to Fonds et al. 352 (1992).

The two "clean" tows without excessive sediment and debris had the lowest mortality. 354 The remaining tows often contained several large lumps of peat, each up to $50-70 \mathrm{~kg}$ that 355 might damage the catch in the codend during the tow. This was evident by a large degree 356 of abrasion and bleeding injuries in tows that retained peat.

357 Several studies have found a correlation between air exposure and discard survival of 358 plaice (van Beek et al., 1990; Ross and Hokenson, 1997; Humborstad et al., 2009; Benoit 359 et al, 2013; Methling et al., 2017). This study shows similar results with a negative correlation 360 between time on deck and survival. However, there is a large variance in the present 361 observations with some fish being on deck for almost 50 minutes surviving, whereas other individuals died after 4 minutes on the deck.

The quality of the water in the fish pound might influence survival (illustrated by deck time). Because of oxygen consumption by the catch, mud and relatively low oxygen saturation (high temperatures) the oxygen level was likely rapidly declining creating a hypoxic environment. However, flatfish are known for superior resilience to low oxygen and air exposure in comparison with roundfish (Broadhurst et al., 2006), and plaice in particular have possible cutaneous $\mathrm{O}_{2}$ uptake (Steffensen et al, 1981). The combination of several stressors might lead to possible cumulative lethal effects (Davis, 2002; Broadhurst et al., 2006).

Previous studies have shown reflex impairment as a tool to predict stress and even delayed mortality in different species of fish (Davis, 2007, 2010; Humborstad et al., 2009, 2016; Methling et al., 2017). Reflex impairment alone was not a strong indicator of delayed mortality in this study. The uncoupling of reflex impairments from the delayed mortality leaves the injuries as the best indicator, which could be useful as mortality predictor since injury assessment can be done in the field without accessories opposed to most reflex impairments. Consequently, using vitality impairment as a mortality predictor for plaice could be plausible, as the results show a high mortality after medium accumulated impairment, i.e. 
several recognizable injuries. It is, however, not without challenges to assess injuries on plaice as its natural camouflage can show resemblance to abrasions while some internal 381 injuries might not be visible immediately.

382 The seabird predation experiment indicated that the majority of plaice below MCRS were 383 eaten or taken by the seabirds (gulls). In a previous study it was estimated that about $60 \%$ of the discarded material (Catchpole et al., 2006) was taken by seabirds. The predation by seabirds adds an additional unquantified contribution to discard mortality and thus might also have a potential influence on the seabird population. The present study, however, had a limited number of observations and there might be other influential factors on seabird predation like vessel speed, discards composition and practice a light level that should be assessed. Consequently our estimate was not an average estimate for this fishery, but an indication that sea gulls potentially are capable of consuming a considerable proportion of dead discarded plaice below a given size. Since sea gulls don't dive but pick up discarded plaice in the air or immediately when they hit the sea surface, it is likely, that alive plaice would also be taken. However this needs further investigations. A discard ban on plaice, might consequently also affect sea bird communities.

The low short-term survival estimated in the present study suggest that plaice caught in Nephrops fisheries might not be an obvious candidate for exception to the landing obligation. Additional experiments would be of importance. Particularly from larger vessels, other areas and with lower deck temperatures.

\section{Acknowledgement}

The authors wish to thank Jørgen Michelsen skipper on TANA and technicians from DTU 403 Aqua for their assistance to conduct the experiments. We highly appreciate comments from reviewers. This study was conducted with financial support from European Maritime and 405 Fisheries Fund (EMFF) and the Danish Ministry of Food, Agriculture, and Fisheries. All experiments were performed in accordance with European and Danish legislation on animal experimentation (Danish Animal Experiments Inspectorate, permit no. 2014-15-0201-00413).

\section{References}


411 Beek, F. van, Leeuwen, P. \& van Rijnsdorp, A. (1990). On the survival of plaice and sole 412 discards in the otter-trawl and beam-trawl fisheries in the North Sea. Netherlands Journal 413 of Sea Research, 26, 151-160.

414 Benoît, H.P., Plante, S., Kroiz, M., \& Hurlbut, T. A., (2013). Comparative analysis of marine 415 fish species susceptibilities to discard mortality: effects of environmental factors, 416 individual traits, and phylogeny. ICES Journal of Marine Science, 70, 99-113.

417 Bergmann, M., Wieczorek, S., Moore, P. \& Atkinson, R. (2002). Discard composition of the 418 Nephrops fishery in the Clyde Sea area, Scotland. Fisheries Research, 57, 169-183.

419 Bicknell, A.W.J., Oro, D., Camphuysen, C.J. \& Votier, S.C. (2013). Potential consequences 420 of discard reform for seabird communities. Journal of Applied Ecology, 50, 649-658.

421 Broadhurst, M. K., Suuronen, P. \& Hulme, A., (2006). Estimating collateral mortality from 422 towed fishing gear. Fish and Fisheries, 7,180-218.

423 Catchpole, T., Frid, C. \& Gray, T., (2005). Discarding in the English north-east coast 424 Nephrops norvegicus fishery: The role of social and environmental factor. Fisheries Research, 72, 45 - 54, 2005.

Catchpole, T., Frid, C. \& Gray, T. (2006). Importance of discards from the English Nephrops norvegicus fishery in the North Sea to marine scavengers. Marine Ecology Progress Series, 313, 215-226, 2006.

Catchpole, T., \& Revill, A.S. (2007). Gear technology in Norway lobster trawl fisheries. Review Fish biology and Fisheries, 18, 17-31

Clarke, A., \& Johnston, N. M. (1999). Scaling of metabolic rate with body mass and temperature in teleost fish. Journal of Animal Ecology, 68, 893-905.

Condie, H. M., Grant, Alastair \& Catchpole, T. (2013). Does banning discards in an otter trawler fishery create incentives for more selective fishing? Fisheries Research, 48, 137146.

438 Davis, M. \& Ottmar, M. (2006). Wounding and reflex impairment may be predictors for 439

Davis, M. (2002). Key principles for understanding fish bycatch discard mortality. Canadian Journal for Fisheries and Aquatic science, 59, 1834-1843. 
Davis, M.W. (2007). Simulated fishing experiments for predicting delayed mortality rates using reflex impairment in re- strained fish. ICES Journal of Marine Science, 64, 15351542.

Davis, M. W. , (2010). Fish stress and mortality can be predicted using reflex impairment. FISH and FISHERIES 11, 1-11.

Depestele, J., Desender, M., Benoît, H.P., Polet, H. \& Vincx, M. (2014). Short-term survival of discarded target fish and non-target invertebrate species in the "eurocutter" beam trawl fishery of the southern North Sea. Fisheries Research, 154, 82-92.

Depestele, J., Doremus, G., Laffargue, P., Stienen, E. W. M., \& Rochet, M. J. (2016). Favorites and leftovers on the menu of scavenging seabirds: modelling spatiotemporal variation in discard consumption. Canadian Journal of Fisheries and Aquatic Sciences, 73: 1446-1459.

Feekings, J., Bartolino, V., Madsen, N, \& Catchpole, T. (2012). Fishery Discards: Factors Affecting Their Variability within a Demersal Trawl Fishery. PLOS ONE 7:e36409.

Fonds, M., Cronie, R. Vethaak, A. \& van Der Puyl, P. (1992). Metabolism, food consumption and growth of plaice (Pleuronectes platessa) and flounder (Platichthys flesus) in relation to fish size and temperature. Netherlands Journal of Sea Research, 29, 127-143.

Fonteyne, R., Buglioni, G., Leonori, I., O'Neill, F.G., Fryer, R.J. (2007). Laboratory and field trials of OMEGA, a new objective mesh gauge. Fisheries Research, 85, 197-201.

Frandsen, R. Holst, R. \& Madsen, N. (2009). Evaluation of three levels of selective devices relevant to management of the Danish Katte-Skagerrak Nephrops fishery. Fisheries Research, 97, 243-252.

Frandsen, R., Madsen, N. \& Krag, L. (2010). Selectivity and escapement behavior of five fishery species in standard square- and diamond-mesh codends. ICES Journal of Marine Science, 67, 1721-1731.

Humborstad, O-B., Davis, M. W. \& Løkkeborg, S. (2009). Reflex impairment as a measure of vitality and survival potential of Atlantic cod (Gadus morhua). Fisheries Bulletin, 107, 395-402.

ICES, (2014a). Report of the workshop on methods for estimating discard survival (WKMEDS). ICES Headquaters, Copenhagen, Denmark. ICES CM. 114 pp.

ICES, (2014b). Report of the workshop on methods for estimating discard survival 2 (WKMEDS2). ICES Headquaters, Copenhagen, Denmark. ICES CM. 35 pp. 
Kaiser, M. J., Spencer, B. E. (1995). Survival of by-catch from a beam trawl. Marine Ecology Progress Series, 126, 31-38.

Kaplan, E. L., Meier, P. (1958). Nonparametric estimation from incomplete observations. Journal of the American Statistical Association, 53, 457- 481.

Krag, L., Frandsen, R., \& Madsen, N. (2008). Evaluation of a simple means to reduce discard in the Kattegat-Skagerrak. Fisheries Research, 91, 174-186.

Madsen, N., Frandsen, R. P., Holst, R., Krag, L. A. (2010). Development of new concepts for escape windows to minimise cod catches in Norway lobster fisheries. Fisheries Research, 103, 25-29.

Madsen, N., Feekings, J., \& Lewy, P. (2013). Discarding of plaice (Pleuronectes platessa) in the Danish North Sea trawl fishery. Journal of Sea Research, 75, 129 - 134.

Methling, C., Skov, P.V. \& Madsen, N., (2017). Reflex impairment, physiological stress, and discard mortality of European plaice Pleuronectes platessa in an otter trawl fishery. ICES Journal of Marine Science, 74, 1660-1671.

Millner, R., Whiting, C. \& Howlett, G. (1993). Estimation of dis-card mortality of plaice from small otter trawlers using tagging and cage survival studies. ICES Counsil Meeting Papers, ICES CM 1993/G:24.

Morfin, M., Kopp, D., Benoît, H.P. Méhault, S. Randall, P., Foster, R.. Catchpole, T., 2017. Survival of European plaice discarded from coastal otter trawl fisheries in the English Channel. Journal of environmental management, 204, 404-412.

Revill, A.S., Broadhurst, M.K., \& Millar, R.B. (2013). Mortality of adult plaice, Pleuronectes platessa and sole, Solea solea discarded from English Channel beam trawlers. Fisheries Research, 147, $320-326$.

Rice, A., \& Chapman, C. (1971). Observations on the burrows and burrowing behaviour of two mud-dwelling decapod crustaceans, Nephrops norvegicus and Goneplax rhomboides. Marine Biology, 10, 330 - 342.

Ross, M. R., \& Hokenson, S. R. (1997). Short-term mortality of discarded finfish bycatch in the Gulf of Maine fishery for Northern Shrimp, Pandalus borealis. North American Journal of Fisheries Management, 17, 902 - 909.

Sardà F, Coll M, Heymans JJ, \& Stergiou K.I. (2015). Overlooked impacts and challenges of the new European discard ban. Fish and Fisheries, 16, 175-180. 
503 Sigurðardóttir, S., Stefánsdóttir, E. K., Condie, H., Margeirsson, S., Catchpole, T.L., Bellido, 504 J.M., Eliasen, S., Goñi, R., Madsen, N., Palialexis, A., Rochet, M. J., Uhlmann, S. S., \& 505 Vassilopoulou, V. (2015). How can discards in European fisheries be mitigated? 506 Strengths, weaknesses, opportunities and threats of potential mitigation methods. Marine 507 Policy, vol 51: 366-374.

508 Steffensen, J. F., Lomholt, J. P., \& Johansen, K. (1981). The relative importance of skin 509 oxygen uptake in the naturally buried plaice, Pleuronectes platessa, exposed to graded $510 \quad$ hypoxia. Respiration Physiology, 44, 269-275.

511 Uhlmann SS, van Helmond ATM, Kemp Stefánsdóttir E, Sigurðardóttir S, Haralabous J, 512 Bellido JM, et al. 2014. Discarded fish in European waters: general patterns and 513 contrasts. ICES Journal of Marine Science, 71, 1235-1245.

514 Uhlmann, S. S., Theunynck, R., Ampe, B., Desender, M., Soetaert, M., \& Depestele, J. 515 (2016). Injury, reflex impairment, and survival of beam-trawled flatfish. ICES Journal of 516 Marine Science, 73, 1244-1254.

517 Votier, S.C., Bicknell, A.W.J., Cox, S.L., Scales, K.L. \& Patrick, S. (2013) A bird's eye view 518 of discard reforms: bird-borne cameras reveal seabird/fishery interactions. PLoS 519 ONE, 8, e57376.

520 Wassenberg, T., \& Hill, B. (1993). Selection of the appropriate duration of experiments to 521 measure the survival of animals discarded from trawlers. Fisheries Research, 17, 343522353. 
523 Table 1 Overview of conducted hauls. Date for start of sea trials, average (Avg.) size and numbers of 524 experimental fish. Depth at start and end of the tow. Control fish are taken from haul 5 and 7.

\begin{tabular}{lcccccccc}
\hline Haul & Date & $\begin{array}{c}\text { Duration } \\
(\mathbf{m i n})\end{array}$ & Depth $(\mathbf{m})$ & \multicolumn{2}{c}{ Size $(\mathrm{mm})$} & & \multicolumn{2}{c}{ Numbers } \\
& & & & Avg. & Range & & Sample & Dead \\
\hline 1 & $29 / 6-2015$ & 160 & $33-53$ & 243 & $193-270$ & & 18 & $17^{1}$ \\
2 & $29 / 6-2015$ & 180 & $28-33$ & 236 & $180-273$ & & 18 & 11 \\
3 & $1 / 7-2015$ & 180 & $33-36$ & 233 & $183-278$ & & 20 & $18^{2}$ \\
4 & $1 / 7-2015$ & 180 & $29-33$ & 224 & $183-266$ & & 20 & 13 \\
5 & $1 / 7-2015$ & 16 & $30-31$ & 217 & $156-266$ & & $20+20$ & $3+0$ \\
6 & $2 / 7-2015$ & 180 & $30-39$ & 228 & $179-289$ & & 20 & 18 \\
7 & $2 / 7-2015$ & 15 & $33-33$ & 216 & $164-256$ & & $20+20$ & $1+0$ \\
8 & $3 / 7-2015$ & 180 & $27-43$ & 232 & $198-269$ & & 20 & 20 \\
9 & $3 / 7-2015$ & 180 & $31-35$ & 228 & $188-265$ & & 20 & 16 \\
\hline
\end{tabular}

$526{ }^{1}$ A single individual disappeared during storing.

5272 Two individuals disappeared during storing. 
528 Table 2 Description of the 3 reflex action mortality predictors. The overall potential score is between 0 and

5293 , with each individual was scored 1 if the specific response was absent (impairment) or 0 when the action $530 \quad$ was completed as described.

\begin{tabular}{lll}
\hline RAMP & Stimulus action & Response \\
\hline Righting & $\begin{array}{l}\text { The plaice is kept on the palm of the hand } \\
\text { on its back at the surface and then } \\
\text { released }\end{array}$ & Actively righting itself underwater \\
Evasion & $\begin{array}{l}\text { The plaice is held by two hands at the } \\
\text { water surface and is gently released }\end{array}$ & $\begin{array}{l}\text { Fish swims actively away (to the } \\
\text { bottom) }\end{array}$ \\
Tail grab & $\begin{array}{l}\text { The tail of the plaice is held between two } \\
\text { fingers }\end{array}$ & Actively struggles and swims away \\
\hline
\end{tabular}


532 Table 3 Description of the injuries assessed. Individuals scored 0 if the damage was absent, or 1 if the damage

533 was present.

\begin{tabular}{ll}
\hline Injury & Description \\
\hline Scale loss & Visible loss of scales from anywhere on the body \\
Fin fraying & $\begin{array}{l}\text { Shredding of the thin skin between the anal, dorsal and/or caudal fin } \\
\text { Abrasion minor }<30 \%\end{array}$ \\
& $\begin{array}{l}\text { Bruises and discoloration on the pigmented upwards facing side } \\
<30 \%\end{array}$ \\
Abrasion major $>30 \%$ & $\begin{array}{l}\text { Bruises and discoloration on the pigmented upwards facing side } \\
>30 \%\end{array}$ \\
Bleeding minor $<30 \%$ & $\begin{array}{l}\text { Spots or patches of visible internal bleeding on the ventral side down } \\
<30 \%\end{array}$ \\
Bleeding major $>30 \%$ & $\begin{array}{l}\text { Spots or patches of visible internal bleeding on the ventral side down } \\
>30 \%\end{array}$ \\
Wounding & A superficial cut or puncture of the skin \\
Deep wounding & A deep cut or puncture of the skin, often with bleeding \\
Internal organ exposure & A sufficiently large wound causing the organs to be exposed \\
Protruding intestine & Intestines being visible through the anus and/or mouth
\end{tabular}


535 Table 4 Injury and RAMP scores for individual hauls and combined injury and reflex impairment score with 536 standard deviation.

\begin{tabular}{|c|c|c|c|c|c|c|c|c|c|}
\hline & \multicolumn{7}{|c|}{ Experimental hauls } & \multicolumn{2}{|l|}{$\begin{array}{c}\text { Control } \\
\text { hauls }\end{array}$} \\
\hline & 1 & 2 & 5 & 4 & 6 & 8 & 9 & 5 & 7 \\
\hline \multicolumn{10}{|l|}{ Injury } \\
\hline Scale loss & 0.83 & 0.33 & 0.75 & 0.85 & 0.95 & 0.95 & 0.80 & 0.60 & 0.50 \\
\hline Fin fraying & 0.72 & 0.72 & 0.60 & 0.60 & 0.75 & 0.65 & 0.75 & 0.15 & 0.40 \\
\hline Abrasion (minor) & 0.56 & 0.39 & 0.20 & 0.70 & 0.25 & 0.40 & 0.70 & 0.60 & 0.65 \\
\hline Abrasion (major) & 0.39 & 0.11 & 0.80 & 0.30 & 0.75 & 0.60 & 0.45 & 0.05 & 0.10 \\
\hline Bleeding (minor) & 0.28 & 0.39 & 0.40 & 0.55 & 0.45 & 0.35 & 0.55 & 0.65 & 0.75 \\
\hline Bleeding (major) & 0.56 & 0.61 & 0.35 & 0.20 & 0.50 & 0.55 & 0.35 & 0.05 & 0.05 \\
\hline Wounding & 0.28 & 0.11 & 0.05 & 0.15 & 0.05 & 0.10 & 0.15 & 0.10 & 0.20 \\
\hline Deep wounding & 0.06 & 0.00 & 0.00 & 0.00 & 0.00 & 0.00 & 0.00 & 0.00 & 0.00 \\
\hline Internal organ exposed & 0.00 & 0.00 & 0.00 & 0.00 & 0.00 & 0.00 & 0.00 & 0.00 & 0.00 \\
\hline Protruding intestine & 0.00 & 0.00 & 0.00 & 0.00 & 0.00 & 0.05 & 0.05 & 0.00 & 0.00 \\
\hline \multicolumn{10}{|l|}{$\underline{R A M P}$} \\
\hline Righting & 0.22 & 0.67 & 0.20 & 0.60 & 0.20 & 0.35 & 0.50 & 0.95 & 1.00 \\
\hline Evasion & 0.06 & 0.22 & 0.10 & 0.40 & 0.15 & 0.10 & 0.15 & 0.95 & 0.95 \\
\hline Tail grab & 0.11 & 0.44 & 0.15 & 0.55 & 0.15 & 0.25 & 0.25 & 0.95 & 1.00 \\
\hline Impairment score & $0.58 \pm 0.13$ & $0.4 \pm 0.13$ & $0.53 \pm 0.11$ & $0.41 \pm 0.17$ & $0.57 \pm 0.10$ & $0.55 \pm 0.09$ & $0.52 \pm 0.19$ & $0.19 \pm 0.14$ & $0.22 \pm 0.09$ \\
\hline
\end{tabular}


541 Figure 1 A) On board holding tanks (300 L) with water supply. B) Transport box with tagged plaice submerged 542 in holding tank.

Figure 2 Short-term mean survival probability with $95 \%$ confidence intervals after 240 hours of (A) the study 545 total with experiment $(\bullet, N=133)$, control method $(\boldsymbol{\bullet}, \mathrm{N}=39)$ and untreated control $(\mathbf{\Lambda}, \mathrm{N}=40)$ or $(\mathrm{B})$ divided 546 between potential contamination of the catch with "dirty $(\circ, N=95)$ and "clean" tows $(\square, N=38)$. In $(A)$ the 547 individual tows are illustrated in the background with a grey dashed line.

Figure 3 Vitality impairment (proportion) to predict (A) mortality (absent/present) in individual plaice or (B) mortality proportion when treating the different tows as separate inputs. The observations, individuals and tow 551 dependent relationships, are added as $\bullet$ in $(A)$ and $(B)$, respectively. Note that several points overlap in both 552 figures.

Figure 4 Seabird predation behaviour on discarded plaice. Behavioural categories provided (see section 2.4) 555 and total length of the plaice. The box plot indicates $10^{\text {th }}$ (1 $1^{\text {st }}$ horizontal line), $25^{\text {th }}$ (start of grey box), $75^{\text {th }}$ (end 556 of grey box) and $90^{\text {th }}$ (last horizontal line) percentiles. The filled line inside the box is the median and the 557 dashed the average total length. The numbers in parenthesis indicates number of observations for each 558 behavioural category. 


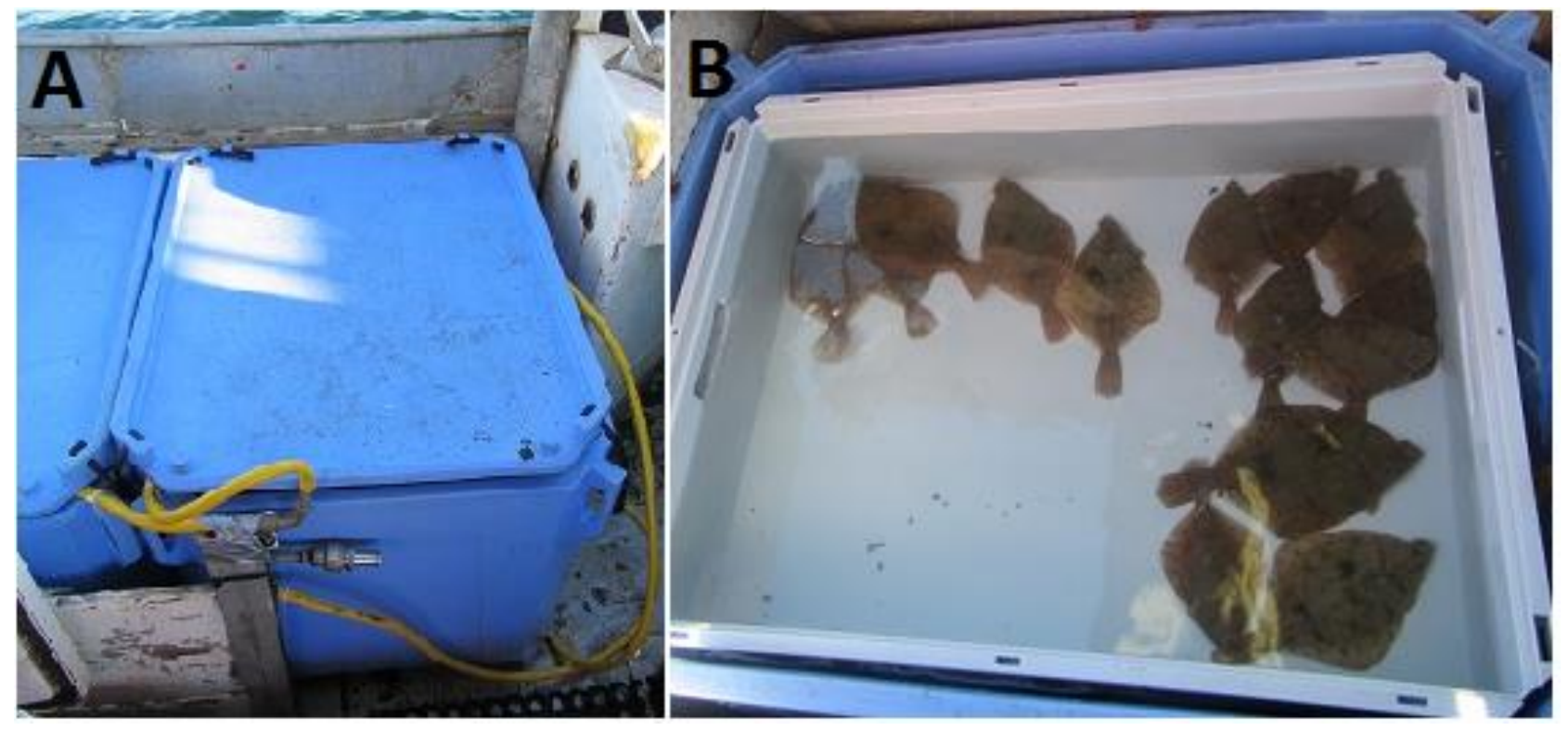

562 Figure $1 \mathrm{~A}$ ) On board holding tanks ( $300 \mathrm{~L}$ ) with water supply. B) Transport box with tagged plaice submerged 563 in holding tank. 
A

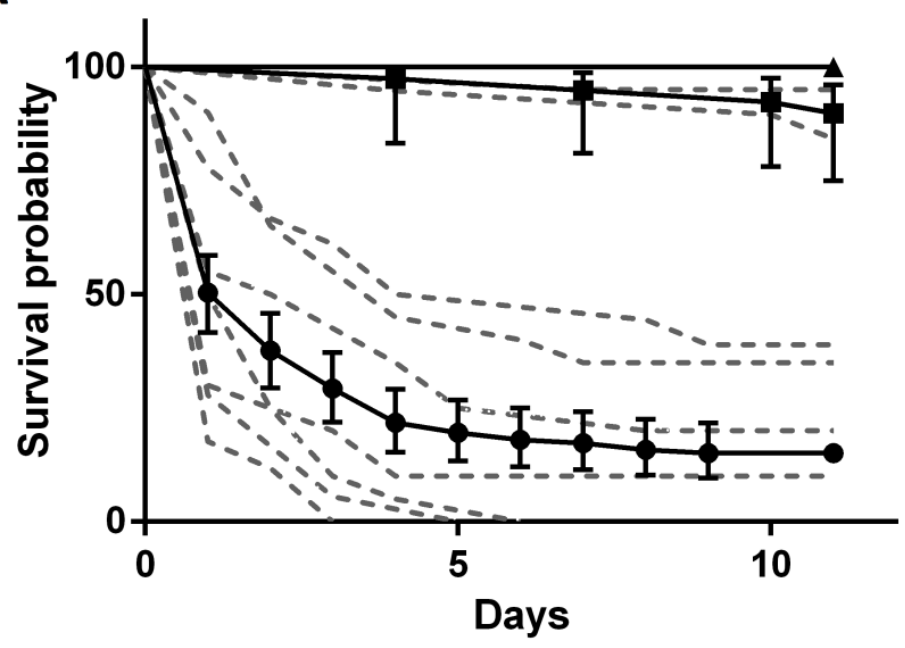

564

B

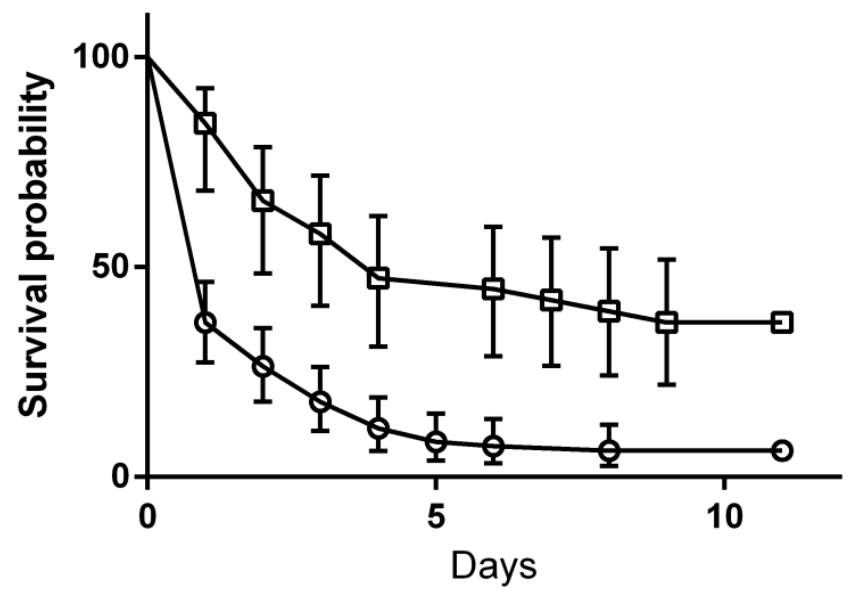

565

566

Figure 2 Short-term mean survival probability with 95\% confidence intervals after 240 hours of (A) the study total with experiment $(\bullet, N=133)$, control method $(\boldsymbol{\bullet}, \mathrm{N}=39)$ and untreated control $(\boldsymbol{\Lambda}, \mathrm{N}=40)$ or $(\mathrm{B})$ divided between potential contamination of the catch with "dirty $(\circ, N=95)$ and "clean" tows $(\square, N=38)$. In $(A)$ the individual tows are illustrated in the background with a grey dashed line. 
A

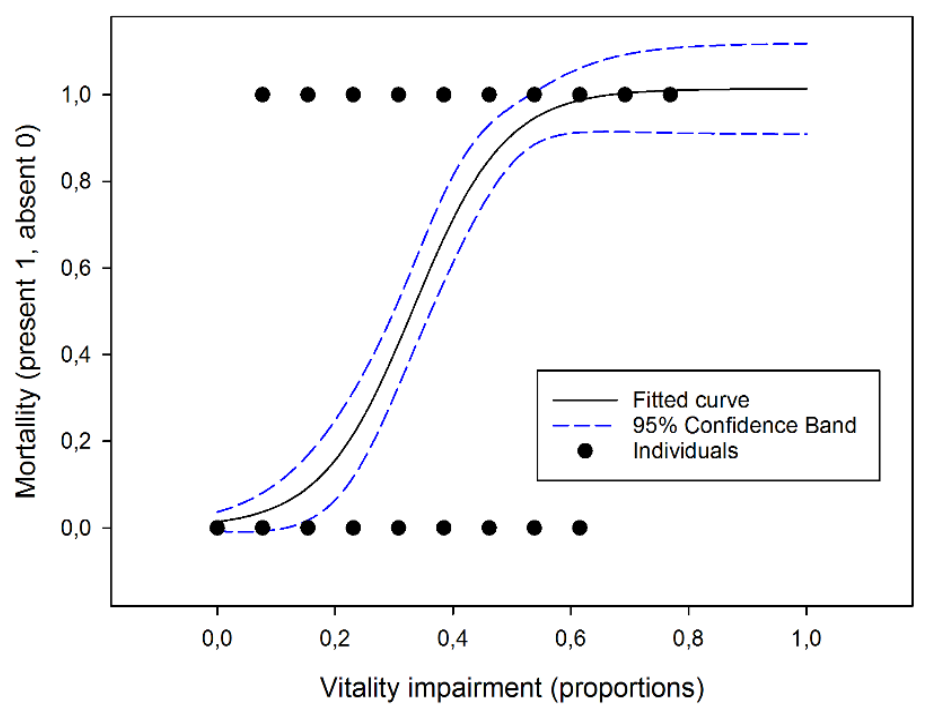

B

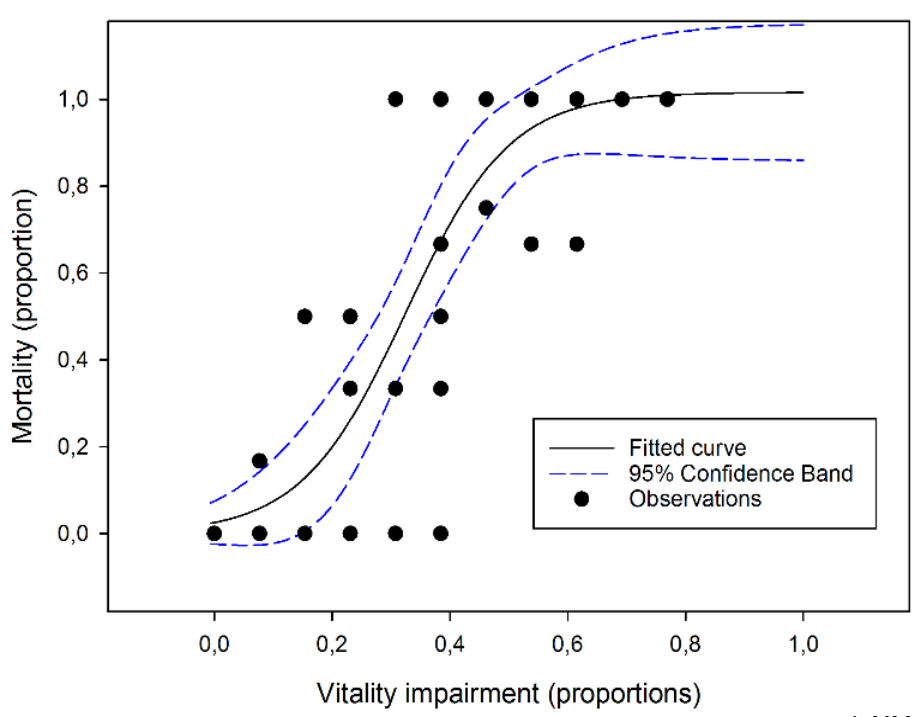

כry

590 Figure 3 Vitality impairment (proportion) to predict (A) mortality (absent/present) in individual plaice or (B) mortality 591 proportion when treating the different tows as separate inputs. The observations, individuals and tow dependent 592 relationships, are added as $\bullet$ in (A) and (B), respectively. Note that several points overlap in both figures. 


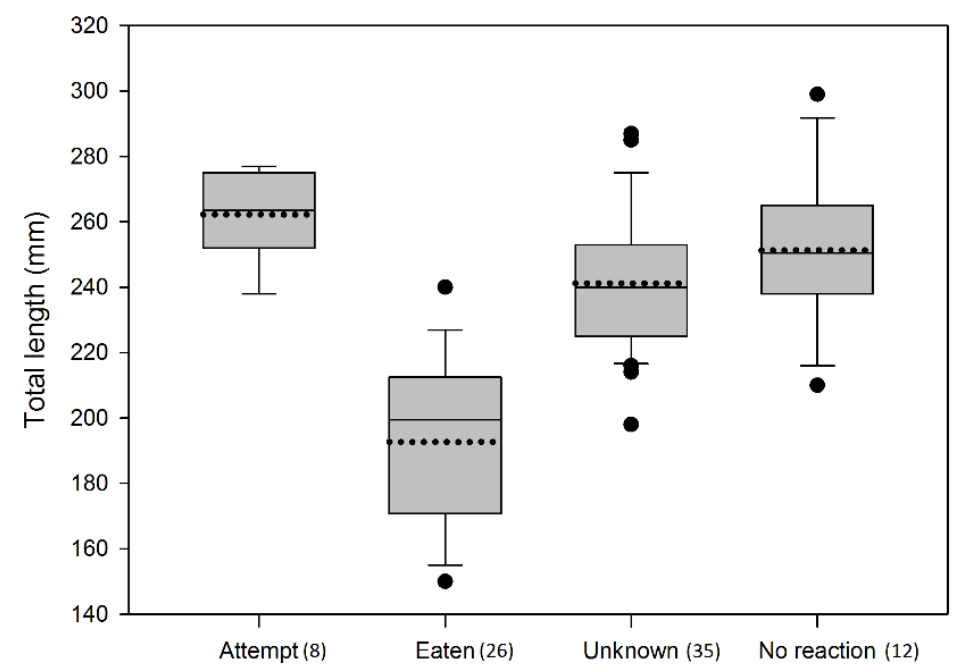

Figure 3 Seabird predation behavior on discarded plaice. Behavioral categories provided (see section 2.4) and total length 598 of the plaice. The box plot indicates $10^{\text {th }}\left(1^{\text {st }}\right.$ horizontal line), $25^{\text {th }}$ (start of grey box $), 75^{\text {th }}$ (end of grey box) and $90^{\text {th }}$ (last 599 horizontal line) percentiles. The filled line inside the box is the median and the dashed the average total length. The 600 numbers in parenthesis indicates number of observations for each behavioral category. 